\title{
O Sistema Único de Assistência Social: resultados da implementação da política nos municípios brasileiros
}

\author{
Pedro Cavalcante \\ Universidade de Brasília \\ Beatriz Bernardes Ribeiro \\ Universidade de Brasília
}

\begin{abstract}
O artigo tem como objetivo desenvolver uma avaliação dos resultados da implementação do Sistema Único de Assistência Social (Suas) após quatro anos da criação. Logo, algumas questões centrais são objeto de avaliação: i) o novo modelo teve impacto na melhoria da gestão municipal? ii) o Suas surtiu resultados positivos do ponto de vista da equidade entre as prefeituras? iii) quais os determinantes de eventuais incrementos na execução local da Assistência Social (AS) após essa mudança institucional? Para tanto, o trabalho emprega os métodos de desenho quase experimental, de análise exploratória de dados e regressão múltipla com base nas informações das pesquisas sobre o Perfil dos Municípios Brasileiros (Munic) do Instituto Brasileiro de Geografia e Estatística (IBGE) de 2005 e 2009. Como resultado, o estudo demonstra que o Suas foi bem-sucedido no incremento da política, redução da disparidade entre os municípios e, principalmente, o processo foi afetado por fatores relativos à dinâmica política eleitoral.
\end{abstract}

Palavras-chave: avaliação; política social; governos municipais.

Aplicación del Sistema Único de Asistencia Social en las ciudades: resultados y determinantes El objetivo es desarrollar una evaluación de la implementación del Sistema Único de Asistencia Social (Suas) tras cuatro años de su creación. Por lo tanto, algunas cuestiones fundamentales son objeto de evaluación: i) El modelo de implementación tuvo un impacto en la mejora de la gestión municipal? ii) El Suas ha tenido resultados positivos en términos de equidad entre los municipios? iii) Qué son los determinantes de posibles incrementos en la implementación local después de este cambio institucional? El artículo emplea los métodos de análisis exploratorio de datos y la regresión múltiple basado en las encuestas Munic/IBGE de 2005 y 2009. Como resultado, el estudio muestra que el Suas ha tenido éxito en la mejora de la política, la reducción de la disparidad entre los municipios y, especialmente, el proceso se vio afectado por factores relacionados con la dinámica de la política electoral.

Palabras clave: evaluación; política social; gobiernos municipales.

Artigo recebido em 15 mar. 2012 e aceito em 17 ago. 2012.

Rev. Adm. Pública - Rio de Janeiro 46(6):1459-77, nov./dez. 2012 
Implementation of the Sistema Unico de Assistencia Social in Municipalities: outcomes and determinants

This paper develops an outputs assessement of the Sistema Unico de Assistencia Social's implementation after four years of its conception. Therefore, some relevant issues are subject of this article analysis: i) has the new implementation framework had an impact on local government improvement? ii) has Suas implementation had positive outputs in reducing inequality among municipalities? iii) What are the determinants of municipalities' improvement in welfare policymaking after this institutional change? In order to do so, data exploratory analysis and multiple regression are employed based on 2005 and 2009 Munic/IBGE surveys. As a result, the inquiry demonstrates that overall Suas has been successful improving the welfare policy, reducing the disparity among municipalities and, especially, political system's aspects impacted the process.

Key WORDS: policy evaluation; social policy; local governments.

\section{Introdução}

O artigo tem como finalidade realizar uma avaliação dos resultados da implementação da política nacional de Assistência Social (AS) após quatro anos da criação do Sistema Único de Assistência Social (Suas), adotando a metodologia de desenho quase experimental com dados da sua implementação em 2005 e após quatro anos da sua criação, 2009.

A política, apesar de ser um dos tripés do sistema de seguridade social brasileiro, até meados da década passada era caracterizada pela fragmentação das ações, atendimento residual e baixo grau de responsabilização governamental. Com a instituição do Suas, em 2005, o modelo de implementação da política foi reorganizado e passou a se fundamentar, sobretudo, na descentralização federativa com definição clara de atribuições, ações intersetoriais e sistema de financiamento compartilhado. Dentro dessa nova estratégia, a esfera municipal se posiciona como um ator protagonista na gestão da assistência social.

Esse processo de mudança apresenta algumas questões centrais na compreensão da política social brasileira que serão objeto de análise deste artigo:

i. A efetividade da criação do Suas na gestão municipal, isto é, verificar se o novo modelo de implementação da AS teve impacto na melhoria da capacidade administrativa das prefeituras e na prestação de serviços assistenciais;

ii. A tentativa de mensurar a criação do Suas para identificar se surtiu resultados positivos do ponto de vista da equidade entre os municípios, isto é, se houve redução na disparidade entre os municípios no que tange à estrutura e ao desempenho na gestão da AS. E também se as prefeituras com gestão da AS incipiente em 2005 evoluíram mais do que aquelas que apresentavam um desempenho melhor; e

iii. A análise a partir de um conjunto de variáveis socioeconômicas, demográficas e, principalmente, de ordem política, dos determinantes de eventuais incrementos na execução 
local da assistência social após a implementação do Suas. O foco é, sobretudo, mensurar se aspectos da dinâmica política influenciaram o processo ou se predominou o caráter impessoal e técnico, conforme orientações no Plano Nacional de Assistência Social (Pnas).

Para tanto, o trabalho se fundamenta em uma abrangente base empírica extraída dos suplementos especiais de assistência social da Pesquisa de Informações Básicas Municipais (Munic/IBGE) dos anos de 2005 e 2009. A partir dessas informações foram elaborados dois indicadores que refletem aspectos centrais da política em todos os municípios do país: a capacidade administrativa das prefeituras nessa área e a provisão de serviços assistenciais. Além da análise descritiva desses indicadores, o artigo utiliza análise de regressão múltipla para mensurar os efeitos que podem ter influenciado a execução municipal da política. O pressuposto a ser testado é de que fatores de natureza política também exercem efeitos nos resultados das prefeituras.

O artigo se inicia com a apresentação das modificações na assistência social pós-Constituição Federal de 1988, enfatizando as alterações introduzidas pelo Pnas de 2004. Em seguida, são discutidas algumas premissas relativas à avaliação de políticas públicas de modo a contextualizar a metodologia da pesquisa. Ademais, os modelos e respectivas variáveis são detalhados, bem como a análise descritiva da evolução da política entre 2005 e 2009. Por fim, os resultados dos modelos são comparados e as considerações finais apresentadas.

\section{A política de assistência social no Brasil}

A Constituição de 1988 introduziu uma nova perspectiva em relação ao foco, objetivos e formas de implementação da política de assistência social no país. Como na saúde, a área passou a ter status de direito do cidadão e responsabilidade do Estado em relação à provisão dos serviços e benefícios. Cinco anos depois, a Lei Orgânica da Assistência Social (Loas) regulamenta a Constituição, ${ }^{1}$ estabelecendo de fato o caráter não contributivo da política ${ }^{2}$ por intermédio da instituição do Benefício de Prestação Continuada (BPC).

A despeito dessas transformações, o campo da prestação de serviços assistenciais não apresentou uma evolução significativa durante a década de 1990, como afirmam Jaccoud, Hadjab e Chaibub (2008:187): "especialmente em termos municipais, o planejamento da política, a avaliação da demanda, o acompanhamento e avaliação dos serviços ofertados pelas entidades beneficentes (...) pouco avançaram em relação ao período anterior".

O diagnóstico indicava insuficiente regulação da política, imprecisão conceitual em relação ao público-alvo e aos serviços, fragmentação e baixo grau de responsabilização na ges-

\footnotetext{
${ }^{1}$ Lei no 8.742 aprovada em 7 de dezembro de 1993.

${ }^{2}$ Cabe ressaltar a existência da Renda Mensal Vitalícia (RMV), criada em 1974; no entanto, o programa não possui natureza não contributiva, pois sua concessão exigia uma contribuição mínima à Previdência Social.
} 
tão governamental e não governamental. A área não possuía unidade de atendimento como referência para o atendimento dos indivíduos e famílias, diferente de serviços públicos como educação e saúde, que têm, respectivamente, a escola e o hospital ou posto de saúde como referências. Em suma, embora a AS constituísse um direito e formalmente fosse parte da estrutura da Seguridade Social brasileira, sua implementação era precariamente organizada, sem coordenação efetiva com os entes federados e com as entidades privadas que ofertavam os serviços.

Entretanto, com a aprovação do $\operatorname{Pnas}^{3}$ em 2004, a área procurou introduzir um novo modelo da política mediante a instituição do Suas. Desse modo, 16 anos depois, o sistema criou as bases do processo de descentralização determinado constitucionalmente, na medida em que define com mais clareza os princípios e as finalidades da AS, como também estabelece as responsabilidades da gestão compartilhada.

Em consonância com o Pnas, foi elaborada a Norma Operacional Básica (NOB/Suas) em 2005, que disciplina as relações federativas, não apenas detalhando as competências de gestão e financiamento, como também consolidando a integração da rede de serviços e instituindo instrumentos para sua articulação. O objetivo é possibilitar a efetivação da descentralização político-administrativa e a consolidação da política no país.

A prestação dos serviços de assistência social passa então a ser dividida em dois níveis, de acordo com as referências estabelecidas no Pnas: Proteção Social Básica (PSB) e Proteção Social Especial (PSE). Na primeira, os Centros de Referência de Assistência Social (Cras) são unidades públicas estatais de base territorial que organizam e coordenam a rede prestadora de serviços locais. Esse nível de proteção busca a prevenção de situações de risco e o fortalecimento de vínculos familiares e comunitários, sendo destinado à população que vive em situação de vulnerabilidade social. No que tange à implementação, o conjunto dos serviços inclui proteção à família, crianças, jovens e idosos. Tais atividades são desenvolvidas tanto nos Cras dos municípios como em órgãos conveniados através do cofinanciamento federal para custeio dessas ações.

Já a PSE é voltada ao atendimento das famílias e indivíduos em situação de risco pessoal e social. Nesse âmbito, são cofinanciados os serviços de acolhimento às crianças, adolescentes e idosos, mulheres vítimas de violência e o atendimento à população em situação de rua. Seus serviços são desenvolvidos no Centro de Referência Especializado da Assistência Social (Creas) e podem ser organizados com base local; por meio de serviços de referência regional, coordenado e executado pelos estados; ou por intermédio de consórcios públicos entre os municípios. Nesse caso, há dois níveis de complexidade: média $^{4}$ e alta. ${ }^{5}$

\footnotetext{
${ }^{3}$ O Pnas regulamenta os artigos 18 e 19 da Loas e foi aprovado pelo Conselho Nacional de Assistência Social (Cnas) por meio da Resolução no 145 , de 15 de outubro de 2004.

${ }^{4}$ Os serviços de proteção social especial de média complexidade oferecem atendimento às famílias e indivíduos com seus direitos violados, mas cujos vínculos familiares e comunitários não foram rompidos.

${ }^{5}$ Os serviços de proteção social especial de alta complexidade são aqueles que garantem proteção integral — moradia, alimentação, higienização e trabalho protegido para famílias e indivíduos que se encontram sem referência e/ou em
} 
Em síntese, o novo modelo se direciona para a instituição da gestão compartilhada na implementação da política de assistência social brasileira. Entre as mudanças, cabe destacar a prevalência de regulação estatal (NOB, portarias, resoluções), organização dos serviços não mais com base em segmentos (crianças, idosos e portadores de deficiência) e sim por níveis de proteção social (básica e especial), perspectiva de integração com outras políticas sociais e, principalmente, foco na distribuição de macrorresponsabilidades entre as esferas de governo.

No tocante à descentralização, a reorganização proposta pelo Pnas e disciplinada pela NOB propõe mudanças significativas dentro do recém-criado Suas. Essa perspectiva é nítida no texto da NOB (MDS, 2005:22)

Um dos seus objetivos é transformar a política de assistência social em uma política realmente federativa, por meio da cooperação efetiva entre União, Estados, Municípios e Distrito Federal (...). A plena concretização do federalismo cooperativo no país requer o aprimoramento de instrumentos legais e institucionais de cooperação intergovernamental. Trata-se, portanto, de uma estratégia fundamental frente à escassez de recursos públicos, à diferenciada capacidade gerencial e fiscal dos entes federados, às profundas desigualdades socioeconômicas regionais e à natureza cada vez mais complexa dos problemas que exigem soluções intersetoriais e intergovernamentais.

O Suas, portanto, busca instituir um modelo de organização da política fundamentado na normatização e padronização dos serviços e da sua rede prestadora e, principalmente, na implantação de uma nova sistemática de financiamento. Bastante influenciado pela experiência da saúde, a gestão financeira da AS passou por modificações em seus mecanismos de transferência de recursos, nos critérios de partilha e na forma de distribuição.

Com a finalidade de garantir a continuidade das ações e fortalecer a coordenação intergovernamental, a primeira mudança consiste na substituição dos antigos convênios firmados entre as esferas de governo por repasses automáticos e regulares. Prioriza-se o mecanismo de repasse denominado fundo a fundo, isto é, direto do Fundo Nacional de Assistência Social (Fnas) para os fundos estaduais e municipais. A transferência via convênios não foi extinta por completo, permanecendo, no entanto, restrita ao apoio de projetos e programas não continuados. Além disso, os antigos valores per capita baseados no número de atendimentos foram substituídos por critérios de partilha mais sofisticados que envolvem, no caso da PSB, o porte populacional dos municípios, a Taxa de Vulnerabilidade Social ${ }^{6}$ e o cruzamento de indicadores socioterritoriais e de cobertura (MDS, 2005). Na PSE, os critérios incluem indicadores relativos ao combate ao trabalho infantil e ao abuso e exploração sexual de crianças e adolescentes.

As transferências aos governos subnacionais se organizam por meio dos Pisos de Proteção Básica e Pisos de Proteção Social Especial. Para fins de repasses, os municípios devem ser

situação de ameaça, necessitando ser retirados do convívio familiar e/ou comunitário.

${ }^{6}$ Essa taxa é composta por sete indicadores que medem a fragilidade do núcleo familiar a partir de dados do Censo Demográfico de 2000/IBGE e da Pesquisa Nacional de Amostra Domiciliar/IBGE (MDS, 2005). 
habilitados ${ }^{7}$ e podem se enquadrar em três níveis de gestão: inicial, básica e plena. No nível primeiro, as prefeituras recebem recursos da União conforme série histórica, e o desenvolvimento das atividades é relativamente restrito. No nível básico, o município tem de assumir a gestão da proteção social básica, incluindo programas, projetos e serviços socioassistenciais que fortaleçam vínculos familiares e comunitários, promovam os beneficiários do BPC e TCR e vigiem direitos violados no território. Para tanto, a NOB estabelece um conjunto mais extenso de incentivos financeiros às prefeituras que se encontram nessa situação.

A última é a gestão plena, que consiste na provisão de todas as ações no âmbito da política de assistência social, sejam elas financiadas pelo Fnas mediante repasse fundo a fundo ou provenientes de isenção de tributos em razão do Certificado de Entidades Beneficentes de Assistência Social (Ceas). Inclui a oferta de programas, projetos e serviços nos dois níveis de proteção social e, além dos incentivos previstos para a gestão básica, os municípios podem também participar da partilha dos recursos dos Programas e Projetos voltados à Promoção da Inclusão Produtiva (MDS, 2005).

Desse modo, os recursos disponíveis são partilhados e distribuídos por ordem de prioridade, observando o cumprimento das exigências de adesão ao Suas, habilitação nos níveis de gestão plena ou básica e distribuição do mínimo estabelecido para cada porte ao maior número possível de municípios.

Por fim, seguindo as definições previstas na CF/88 e na Loas, o financiamento da gestão da política de assistência social pressupõe percentual de participação de cada ente federado. Embora a questão ainda não tenha sido regulamentada, a NOB define os municípios como protagonistas no financiamento dos serviços de proteção básica e especial, independentemente do porte populacional. Na prática, o monitoramento do orçamento da área (MDS, 2009) demonstra que o processo de municipalização do financiamento vem ocorrendo, embora de forma mais lenta do que preconizado pelo arcabouço normativo da política.

\section{Metodologia da pesquisa}

\subsection{Avaliação de políticas públicas}

De acordo com seus objetivos, este artigo se enquadra numa pesquisa avaliativa na medida em que procura desenvolver uma verificação não apenas da evolução da implementação da política de assistência social no âmbito municipal, como também se propõe a identificar e mensurar a influência de uma série de variáveis que visam representar múltiplas dimensões sobre esse processo.

A avaliação tem, dentre outras finalidades (Weiss, 1998), contribuir para o aperfeiçoamento de um programa ou ação governamental, seja por meio do alcance de melhores resul-

\footnotetext{
${ }^{7}$ No caso dos municípios não habilitados, a gestão dos recursos federais destinados ao cofinanciamento das ações continuadas de assistência social é de responsabilidade do gestor estadual.
} 
tados, proporcionando uma melhor utilização e controle dos recursos neles aplicados, ou pela disponibilização de informações importantes para o desenho de políticas mais consistentes e para a gestão pública mais eficaz (Costa e Castanhar, 2003).

Cabe ressaltar que, assim como as conceituações e as percepções das suas funções, a avaliação também possui uma diversidade de metodologias, modalidades e tipologias. Nosso interesse neste artigo, todavia, concerne à discussão dos desenhos de pesquisa avaliativa, como também à identificação da forma que melhor se ajusta aos objetivos desta investigação, isto é, avaliar os efeitos da mudança na implementação de uma ampla política.

Trata-se, assim, de uma avaliação de insumos-resultados (inputs-outputs) que, de modo geral, procura descrever, entender o relacionamento entre variáveis e rastrear a sequência causal de uma variável para outra (Weiss, 1998). Seus desenhos, entretanto, vão desde os mais simples aos mais complexos, cada um possui utilidade para seu propósito, como também limitações. Roos (1973) argumenta que, nesse caso, algumas questões ajudam o pesquisador a definir a estratégia adequada; são elas:

As variáveis relevantes podem ser medidas? Os pesquisadores sabem operacionalizar importantes insumos e resultados dos programas e grupos de controle? Existem dados disponíveis apropriados ou os pesquisadores têm fundos substanciais para criar dados? Qual é a perspectiva temporal? Série temporal é disponível? (Roos, 1973:299)

A partir dessas questões, os desenhos da pesquisa avaliativa podem variar consideravelmente de situações em que o programa possui objetivos definidos e alto grau de conhecimento obtido a programas com objetivos indefinidos e pouca informação. O quadro 1 apresenta um ordenamento entre os desenhos de estratégias avaliativas possíveis.

\section{Quadro 1 \\ Desenhos de pesquisa avaliativa}

\begin{tabular}{|c|c|c|c|c|c|}
\hline Desenho de processo & Desenho experimental \\
\hline I & II & III & IV & VI \\
\hline $\begin{array}{c}\text { Monitoramento } \\
\text { descritivo }\end{array}$ & Auditoria & $\begin{array}{c}\text { Avaliação Expost } \\
\text { com controles } \\
\text { similares (Matched) }\end{array}$ & $\begin{array}{c}\text { Um grupo } \\
\text { pré-teste e } \\
\text { pós-teste }\end{array}$ & $\begin{array}{c}\text { Desenho com um } \\
\text { grupo de controle } \\
\text { pré-teste e pós-teste }\end{array}$ & $\begin{array}{c}\text { Desenho com um de controle pré- } \\
\text { teste e pós-teste com } \\
\text { seleção aleatória }\end{array}$ \\
\hline
\end{tabular}

Fonte: Adaptação de Caporaso e Roos (1973).

Os desenhos variam de acordo com os níveis de validade, quanto mais à direita mais robustas as análises. Nas avaliações de insumos-resultados, a validade é um aspecto central que significa a veracidade das conclusões, isto é, o fato de as descobertas descreverem a forma como as coisas de fato são. A validade interna remete à ligação causal entre insumos de programas e resultados observáveis, enquanto a externa envolve a capacidade de a descoberta ser generalizável, ser aplicada em outros casos de tipo similar. 
Se, por um lado, os desenhos quase experimentais possuem limitações quanto à validade interna, por outro, eles podem prover moderadamente fortes evidências sobre o impacto de um programa ou intervenção e também têm como vantagem possibilitar maior validade externa, além de serem mais viáveis do que o método experimental (Caporaso e Roos, 1973; Trochim e Donnelly, 2008). Observa-se, portanto, a existência de um trade off entre validades interna e externa no qual o avaliador tem de considerar o que vale mais em um caso particular e escolher o desenho de pesquisa que melhor se ajusta à situação. Além disso, é possível também reduzir as ameaças às validades interna e externa das avaliações mediante o uso de indicadores múltiplos, múltiplas replicações, amostras de um número grande de pontos no tempo e utilizar análises de dados avançadas, como análise fatorial, regressão múltipla e modelos causais (Caporaso e Roos, 1973; Weiss, 1998; Trochim e Donnelly, 2008).

\subsection{Métodos da pesquisa}

A lógica subjacente do desenho avaliativo ideal para estudos de resultados consiste em duas frentes: i) em comparar os participantes dos programas antes de receberem o programa com suas situações após o programa, de modo a verificar se eles tiveram ganhos em resultados importantes; ii) comparar os participantes do programa com um grupo equivalente de pessoas que não receberam o programa, de modo a verificar se os ganhos dos participantes excederam aqueles ganhos pelos não participantes.

Entretanto, como a unidade de análise é a gestão municipal de AS dos municípios brasileiros e ela encontra-se em todas as prefeituras do país, não é possível utilizar nem grupo de controle sem o tratamento e nem seleção aleatória. Para fins de comparação, será utilizada uma variável dos mesmos municípios relativa ao momento anterior à criação do Suas como variável explicativa, e a variável resposta, a diferença entre essa mesma variável e o momento posterior, o que possibilita a mensuração de seus efeitos. Essa forma foi adotada como uma tentativa de enquadrar o desenho quase-experimental como um teste antes e depois (one group pretest-posttest design). Isto é, um único grupo selecionado de forma não aleatória é observado antes e depois do tratamento (a política), como ilustrado abaixo:

$$
\mathrm{O}_{1} \quad \mathrm{X}_{\text {tratamento }} \quad \mathrm{O}_{2}
$$

Cabe salientar a existência de fragilidades desse método no tocante à validade interna, haja vista as ameaças do tipo maturação, história e instrumentalização (Trochim e Donnelly, 2008). Porém, a escolha dessa estratégia é a mais apropriada e viável em função da disponibilidade de dados.

Para comparar a evolução da política entre os anos de 2005 e 2009, o trabalho utiliza análise exploratória de dados com base em dois indicadores da gestão municipal de AS que refletem as condições administrativas e a provisão de serviços assistenciais. A ênfase da análise é não apenas para saber se houve ou não evolução, mas também se ocorreu redução na variação da média desses indicadores. Quanto à análise dos determinantes dos resultados desse 
processo, a pesquisa utiliza regressão múltipla de corte transversal (cross section) a partir do seguinte modelo:

$$
Y=\beta_{\mathrm{i}} X+\varepsilon
$$

Onde,

Y: é o vetor de observações explicadas/dependentes. A diferença entre os indicadores da gestão municipal antes e depois da criação do Suas $\left(\mathrm{X}_{2}-\mathrm{X}_{1}\right)$;

$\beta_{\mathrm{i}}$ : é o vetor de parâmetros que mensuram os efeitos relativos às variáveis explicativas da matriz X;

X: é a matriz de variáveis explicativas/independentes com todas as variáveis (indicadores de 2005, políticas, socioeconômicas e demográficas);

$\varepsilon$ : é o vetor dos erros, supondo que têm distribuição normal com média igual a zero e variância $\sigma^{2} I_{n}$.

\subsection{Variáveis do modelo}

A variável a ser explicada ou dependente é a diferença na gestão municipal da AS entre os anos de 2005 e 2009, ou seja, antes e depois da implementação do Suas. A gestão é representada por meio de índices que refletem as dimensões de capacidade administrativa e provisão de serviços. Eles consistem em indicadores sintéticos elaborados com base em um conjunto de informações disponíveis nos suplementos Assistência Social da Pesquisa de Informações Básicas Municipais (Munic/IBGE) de 2005 e 2009. ${ }^{8}$

Os suplementos levantaram dados sobre a gestão da política a partir da aplicação de questionários compostos de uma série de temas, desde infraestrutura do órgão gestor à prestação de serviços assistenciais.

Embora a versão de 2009 seja mais completa, as variáveis que compõem os indicadores sintéticos, expostas nos quadros 2 e 3, obviamente, estão restritas àquelas presentes nas duas edições.

Quadro 2

Provisão de serviços assistenciais

\begin{tabular}{|lc|}
\hline Critério & \multicolumn{1}{c|}{ Valores } \\
\hline Quantitativo de atividades para execução de serviços socioassistenciais & 1 - todos os treze; fração de 1 - resto \\
\hline
\end{tabular}

Fonte: Suplemento AS da Munic/IBGE de 2005 e 2009. Elaboração própria.

\footnotetext{
${ }^{8}$ A Munic é uma pesquisa realizada pelo IBGE, em todos os municípios brasileiros, que busca obter informações relacionadas à gestão das prefeituras.
} 
Quadro 3

\section{Capacidade administrativa}

\begin{tabular}{|c|c|c|c|}
\hline Critério & Indicadores & Valores & Peso \\
\hline Órgão gestor & Órgão exclusivo & 1 - secretaria exclusiva; 0 - resto & $10 \%$ \\
\hline \multirow{5}{*}{$\begin{array}{l}\text { Legislação e } \\
\text { instrumentos } \\
\text { de gestão }\end{array}$} & A Lei Orgânica trata da assistência social & 1 - sim; 0 - não & \multirow{5}{*}{$30 \%$} \\
\hline & Outro instrumento legal que regulamenta a assistência social & 1 - sim; 0 - não & \\
\hline & Objeto regulamentado por instrumento legal & 1 - todos; fração de 1 - resto & \\
\hline & Existência de Plano & 1 - sim; 0 - não & \\
\hline & Frequência avaliação & $\begin{array}{l}1 \text { - mensal ou trimestral; 0,5 } \\
\text { semestral ou anual; } 0 \text { - resto }\end{array}$ & \\
\hline \multirow{3}{*}{$\begin{array}{l}\text { Recursos } \\
\text { financeiros }\end{array}$} & Fundo Municipal AS & 1 - sim; 0 - não & \multirow{3}{*}{$25 \%$} \\
\hline & FMAS é unidade orçamentária & 1 - sim; 0 - não & \\
\hline & Definição legal de \% & 1 - sim; 0 - não & \\
\hline \multirow{3}{*}{$\begin{array}{l}\text { Convênios e } \\
\text { parcerias }\end{array}$} & Legislação de convênios e/ou parcerias & 1 - sim; 0 - não & \multirow{3}{*}{$20 \%$} \\
\hline & Executa convênios e/ou parcerias & 1 - todos; fração de 1 - resto & \\
\hline & Participa de outros convênios e/ou parcerias & 1 - sim; 0 - não & \\
\hline \multirow{3}{*}{$\begin{array}{l}\text { Conselho de } \\
\text { assistência } \\
\text { social }\end{array}$} & Existência de conselho & 1 - sim; 0 - não & \multirow{3}{*}{$15 \%$} \\
\hline & O conselho é paritário & 1 - sim; 0 - não & \\
\hline & O conselho realizou reunião nos últimos 12 meses & 1 - sim; 0 - não & \\
\hline
\end{tabular}

Fonte: Suplemento AS da Munic/IBGE de 2005 e 2009. Elaboração própria.

É importante ressaltar que em 2005 a Munic não incorporava a nova metodologia de implementação da política com a divisão entre Proteção Social Básica e Especial, bem como seus níveis de gestão. Certas informações relevantes, como as modalidades de atendimento da AS no município, tiveram suas configurações muito alteradas, sobretudo, com a criação dos Cras e Creas e, assim, não puderam ser objeto de verificação, uma vez que não constam na versão de 2005 da Munic. Ou seja, para que fosse possível comparar os indicadores dos dois períodos foi necessário escolher apenas as variáveis comuns aos dois períodos. O fato de não existirem informações acerca da evolução dessas variáveis no período anterior a 2005 é outra limitação na avaliação da política, em que pese à evolução da Munic em coletar informações sobre o tema de forma mais completa. Em síntese, esses dois obstáculos se configuram como restrições à validade interna desta pesquisa, na medida em que se configuram como ameaças de instrumentalização e de história, respectivamente.

Quanto às variáveis independentes ou explicativas de ambos os modelos — um modelo para explicar a Capacidade Administrativa e outro para explicar a Provisão dos Serviços —, elas são separadas nas dimensões: política prévia, político-eleitoral e socioeconômicos/demográficos (quadro 2). 
A primeira dimensão consiste nos indicadores sintéticos de capacidade administrativa e provisão de serviços nos municípios em 2005. As variáveis de política prévia refletem o histórico de implementação da AS pelas prefeituras e, caso apresentem forte influência sobre as variáveis dependentes, podem indicar que não houve alteração na disparidade entre os municípios após a criação do Suas.

O segundo grupo de variáveis, político-eleitoral, visa testar se fatores do sistema político tiveram influência na implantação do novo modelo da assistência, com base na vertente teórica de que a "política importa" na explicação do processo decisório e dos resultados das políticas públicas (Imbeau, Pétry e Lamari, 2001). A primeira variável é Competição Eleitoral. ${ }^{9}$ Espera-se, assim, que o grau de competição nas eleições atue como ameaça aos políticos locais de modo a estimular e controlar o desempenho das suas atividades, servindo como um fator gerador de accountability. As variáveis Prefeito do Partido dos Trabalhadores (PT) e Prefeito do Partido do Governador visam captar a influência do alinhamento partidário, isto é, se as diferenças políticas facilitam ou atrapalham a cooperação em torno da implementação da política pública, conforme a literatura indica (Cox e McCubbins, 1986; Arretche e Rodden, 2004). Com relação ao PT, o objetivo é mensurar eventuais efeitos do pertencimento do gestor local no mesmo partido responsável pela criação e implementação do Suas no nível federal. Por fim, devido à relevância das relações entre Executivo-Legislativo nos resultados das políticas públicas (Stein et al., 2007), a variável Fragmentação da Câmara Municipal se apresenta como uma forma de medir seus efeitos. O pressuposto é que, em caso de uma legislatura muito fragmentada, o número grande de partidos com representantes atue como um indicativo de ponto de veto às decisões do prefeito, podendo dificultar a implementação de mudanças nas políticas públicas.

No último grupo de variáveis, para capturar as nuances relacionadas às condições socioeconômicas da municipalidade são utilizadas as variáveis Situação Econômica do Município e Anos de Estudo da População. No que tange à dimensão demográfica, as variáveis são Porte Populacional e uma variável dummy, Município das Regiões Norte e Nordeste, que procura verificar se o fato de o município pertencer a essas regiões, historicamente menos desenvolvidas, tem influência sobre as variáveis dependentes da pesquisa. Finalmente, a variável Quadro da Administração Pública Municipal reflete as condições da prefeitura em termos de quantitativo da burocracia local.

\footnotetext{
${ }^{9}$ Existem diversas formas de se calcular a competição eleitoral, mas o método mais utilizado é o Número Efetivo de Partidos (NEP) que ganhou uma versão mais sofisticada elaborada por Grigorii Golosov (2010): $N_{p}=\sum_{i=1}^{x} \frac{1}{1+\left(\frac{s_{1}^{2}}{s_{i}}\right)-s_{i}}$ $\left(\mathrm{N}_{\mathrm{p}}\right.$ : indicador de competição político-partidária por ano eleitoral, $\mathrm{S}_{1}$ : é a maior componente, ou seja, a maior proporção na divisão de votos partidários, $\mathrm{S}_{\mathrm{i}}$ : é a outra ou outras componentes de proporção na divisão de votos partidários, x: é o menor componente, ou seja, a menor proporção na divisão de votos partidários).
} 
Quadro 4

Descrição das variáveis de ambos os modelos

\begin{tabular}{|c|c|c|c|}
\hline Variável & Cálculo & Fonte & Período \\
\hline $\begin{array}{l}\text { Indicador multivariado } \\
\text { de capacidade } \\
\text { administrativa e de } \\
\text { provisão de serviços }\end{array}$ & 0 a 1 & Munic/IBGE & 2005 \\
\hline Competição eleitoral & $\begin{array}{l}\text { Número efetivo de partidos } \\
\text { (Golosov, 2012) }\end{array}$ & $\begin{array}{c}\text { Tribunal Superior Eleitoral } \\
\text { - TSE }\end{array}$ & $\begin{array}{c}\text { Eleições de } 2000,2004 \text { e } \\
2008\end{array}$ \\
\hline Prefeito do PT & $\begin{array}{c}1 \text { para caso afirmativo; } 0 \text { para o } \\
\text { oposto }\end{array}$ & $\begin{array}{c}\text { Tribunal Superior Eleitoral } \\
- \text { TSE }\end{array}$ & Eleições de 2004 \\
\hline $\begin{array}{l}\text { Prefeito do partido do } \\
\text { governador }\end{array}$ & $\begin{array}{l}2 \text { para caso afirmativo em duas } \\
\text { situações, } 1 \text { para afirmativo em } \\
\text { uma situação e } 0 \text { caso negativo }\end{array}$ & $\begin{array}{c}\text { Tribunal Superior Eleitoral } \\
- \text { TSE }\end{array}$ & $\begin{array}{c}\text { Prefeito - eleições de } 2004 \\
\text { Governador - eleições de } \\
2002 \text { e } 2006\end{array}$ \\
\hline $\begin{array}{l}\text { Fragmentação da } \\
\text { Câmara dos Vereadores }\end{array}$ & $\begin{array}{c}\text { Razão do número de partidos } \\
\text { com representação sobre o } \\
\text { total de cadeiras na Câmara } \\
\text { Municipal }\end{array}$ & $\begin{array}{c}\text { Tribunal Superior Eleitoral } \\
- \text { TSE }\end{array}$ & Eleições de 2004 \\
\hline $\begin{array}{l}\text { Situação econômica do } \\
\text { município }\end{array}$ & $\begin{array}{l}\text { IFDM - Trabalho e renda é } \\
\text { composto por um conjunto de } \\
12 \text { variáveis que mensuram as } \\
\text { dimensões de emprego formal e } \\
\text { salário médio da população }\end{array}$ & $\begin{array}{c}\text { Índice Firjan de } \\
\text { Desenvolvimento Municipal } \\
\text { - IFDM/Firjan }\end{array}$ & 2007 \\
\hline Porte populacional & $\begin{array}{c}1 \text { - Até } 5.000 ; 2-5.001 \text { até } \\
\text { 10.000; } 3-10.001 \text { até } 20.000 \\
4-20.001 \text { até } 50.000 \\
5-50.001 \text { até } 100.000 \\
6-100.001 \text { até } 500.000 \\
7-\text { maior que } 500.000\end{array}$ & Munic/IBGE & 2009 \\
\hline $\begin{array}{l}\text { Anos de estudo da } \\
\text { população }\end{array}$ & $\begin{array}{c}\text { Razão entre o somatório de } \\
\text { número de anos de estudo } \\
\text { completados pelas pessoas que } \\
\text { têm } 25 \text { anos ou mais de idade } \\
\text { e o número de pessoas nessa } \\
\text { faixa etária }\end{array}$ & Censo Demográfico/IBGE & 2000 \\
\hline $\begin{array}{l}\text { Município das regiões } \\
\text { Norte e Nordeste }\end{array}$ & $\begin{array}{l}1 \text { para afirmativo; } 0 \text { para o } \\
\text { oposto }\end{array}$ & Munic/IBGE & 2009 \\
\hline $\begin{array}{l}\text { Quadro da } \\
\text { administração pública } \\
\text { municipal }\end{array}$ & $\begin{array}{l}\text { Razão entre o total de } \\
\text { funcionários públicos sobre a } \\
\text { população do município }\end{array}$ & Munic/IBGE & 2008 \\
\hline
\end{tabular}

Fonte: Elaboração própria 


\section{Análise dos resultados}

Com relação à efetividade da criação do Suas na melhoria na gestão municipal, é perceptível o efeito positivo praticamente em todo o território nacional, tanto na estrutura administrativa da prefeitura quanto na prestação de serviços assistenciais.

Quanto à capacidade administrativa, a comparação média dos indicadores de 2005 a 2009 (gráfico 1) indica que houve um avanço da estruturação das prefeituras com um incremento generalizado em todas as grandes regiões brasileiras e com um aumento médio de aproximadamente $14 \%$. Por outro lado, observa-se também que após esses quatro anos o desvio padrão do indicador não apresentou mudança significativa, mantendo-se na faixa de 0,1 . Não houve nesse aspecto aumento e nem diminuição da disparidade de condições estruturais na implementação municipal desta política pública.

\section{Gráfico 1}

Evolução da capacidade administrativa (2005 a 2009)

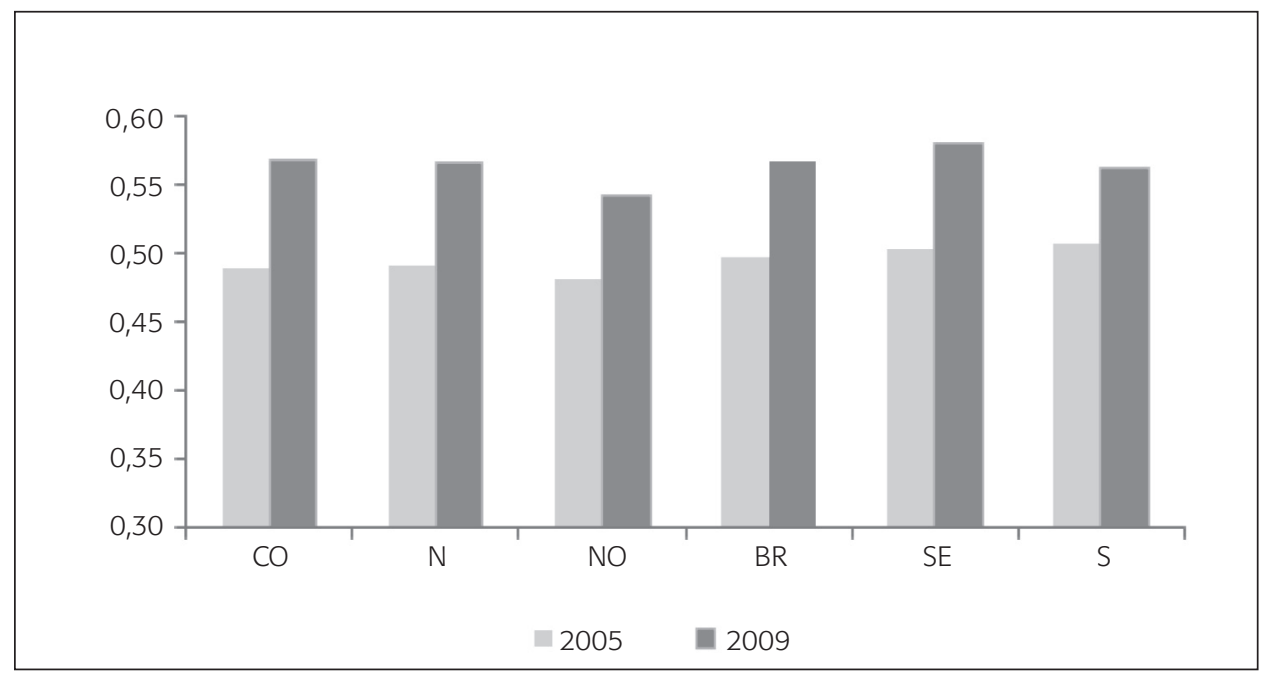

Fonte: Suplemento AS da Munic/IBGE de 2005 e 2009. Elaboração própria.

No que tange à provisão de serviços, os dados demonstram um incremento na quantidade de serviços prestados pelos municípios. A média nacional teve um aumento no indicador em torno de $7 \%$, enquanto o desvio padrão reduziu de 0,25 para 0,22 , indicando que a política de AS após 2005 apresentou uma evolução na prestação de serviços assistenciais e um maior equilíbrio entre as prefeituras, com destaque, principalmente, para os municípios do Nordeste e do Centro-Oeste. À exceção do Sul do país, que foi a única região com diminuição na média geral desse indicador. 
Gráfico 2

\section{Evolução da provisão de serviços (2005 a 2009)}

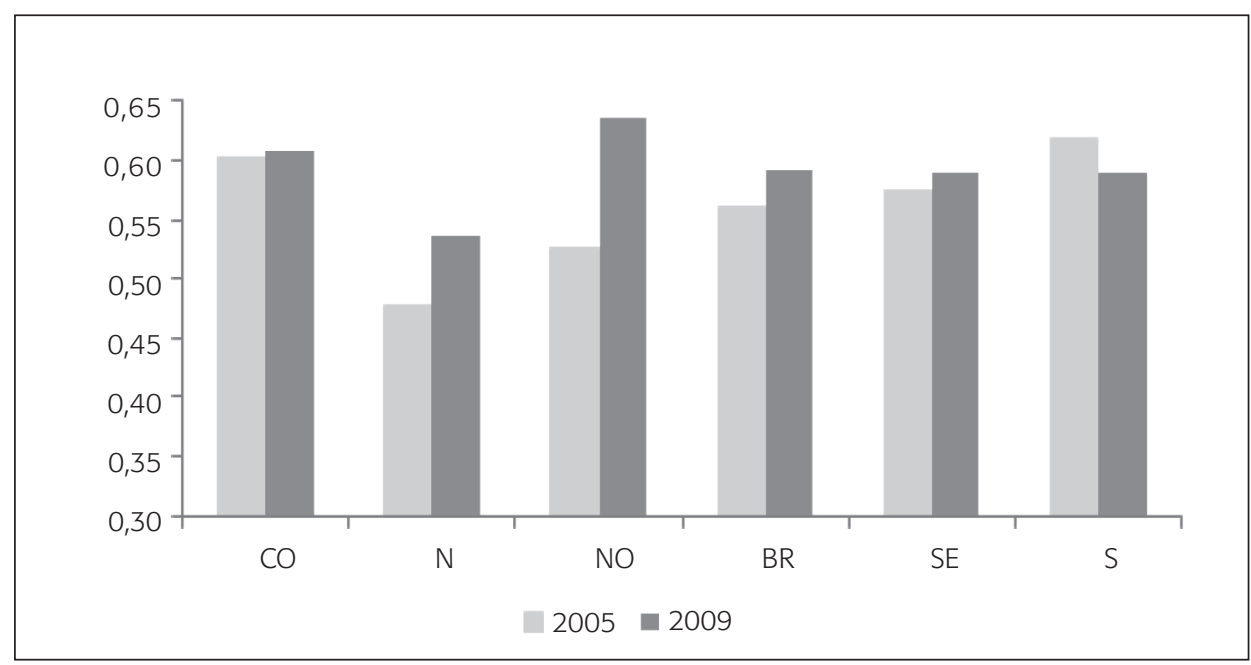

Fonte: Suplemento AS da Munic/IBGE de 2005 e 2009. Elaboração própria.

Com base na análise exploratória dos dados, é possível verificar que o Suas foi bem-sucedido, mesmo na análise restrita a quatro anos. Notam-se não apenas incremento nas duas dimensões de AS analisadas, melhorias em regiões mais pobres, bem como redução da disparidade em média entre os municípios no tocante à provisão de serviços assistenciais.

Não obstante, esse tipo de análise descritiva não possibilita a mensuração dos determinantes desse processo de implementação da política de AS. Para tanto, os coeficientes de regressão de cada uma das variáveis, como também suas respectivas estatísticas de teste (p-valor) dos modelos de regressão múltipla apresentam resultados relevantes para subsidiar essa avaliação. Os modelos foram elaborados de modo a investigar as possíveis influências das dimensões consideradas relevantes na explicação dos resultados dos indicadores construídos.

Os modelos da pesquisa foram construídos com uma relação expressiva de unidades de observações, cerca de 5.400 municípios, ${ }^{10}$ número mais que suficiente para estimação dos parâmetros do modelo. Embora chamem a atenção os efeitos díspares das variáveis dos modelos, em relação à capacidade administrativa cerca de $35 \%$ é explicado, enquanto na análise da provisão de serviços o coeficiente de determinação chega a quase $50 \%$.

\footnotetext{
${ }^{10}$ Não foi utilizada a totalidade dos municípios brasileiros devido à diferença entre os anos dos indicadores e também em razão da codificação municipal distinta, em uma parte dos municípios não havia coincidência em todas as bases de dados.
} 
Tabela 1

Resultados dos modelos da pesquisa

\begin{tabular}{|c|c|c|c|c|}
\hline \multirow[b]{2}{*}{ Variável } & \multicolumn{2}{|c|}{ Capacidade administrativa } & \multicolumn{2}{|c|}{ Provisão de serviços } \\
\hline & $\begin{array}{c}\text { Estimativa do } \\
\text { parâmetro (Beta) }\end{array}$ & P-Valor & $\begin{array}{c}\text { Estimativa do } \\
\text { Parâmetro (Beta) }\end{array}$ & P-Valor \\
\hline Posição de serviços (2005) & & & $-0,728$ & $0,000^{* * *}$ \\
\hline Capacidade administrativa (2005) & $-0,623$ & $0,000^{* * *}$ & & \\
\hline Competição eleitoral & $-0,009$ & 0,429 & $-0,042$ & $0,000^{* * *}$ \\
\hline Prefeito do PT & 0,014 & 0,205 & 0,028 & $0,004 * *$ \\
\hline Prefeito do partido do governador & $-0,003$ & 0,796 & 0,004 & 0,668 \\
\hline Fragmentação da Câmara dos Vereadores & 0,025 & $0,026^{*}$ & 0,002 & 0,876 \\
\hline Situação econômica do município & $-0,002$ & 0,874 & $-0,018$ & 0,159 \\
\hline Porte populacional & 0,099 & $0,000^{* * *}$ & 0,182 & $0,000^{* * *}$ \\
\hline Anos de estudo da população & 0,040 & $0,029 *$ & $-0,030$ & $0,06^{*}$ \\
\hline Municípios das regiões Norte e Nordeste & $-0,017$ & 0,289 & 0,009 & 0,523 \\
\hline Quadro da administração pública municipal & 0,010 & 0,438 & 0,012 & 0,295 \\
\hline$R_{2}$ & \multicolumn{2}{|l|}{0,351} & \multicolumn{2}{|c|}{0,498} \\
\hline $\mathrm{N}$ & \multicolumn{2}{|l|}{5538} & \multicolumn{2}{|c|}{5538} \\
\hline
\end{tabular}

* Nível de significância a 90\%; ** Nível de significância a 95\%; *** Nível de significância a 99\%.

Fonte: Elaboração própria.

Ainda respondendo à questão do caráter redistributivo da implementação do Suas, a primeira variável indica resultados positivos. Nos dois modelos, os indicadores de política prévia (Capacidade Administrativa e Provisão de Serviços em 2005) apresentam significância estatística e forte efeito sobre as variáveis dependentes. Os coeficientes negativos indicam que, quanto mais altos os indicadores dos municípios em 2005, menores foram suas evoluções em 2009. Em outras palavras, sugere que foram priorizadas as prefeituras com gestão de AS incipientes antes do Suas e, com isso, passaram a se estruturar melhor e prestar um maior número de serviços assistenciais.

Quanto aos fatores relativos ao sistema político, os resultados indicam, de modo geral, pouco impacto sobre a evolução da política municipal. Os resultados implicam dizer que a implementação da AS entre 2005 e 2009 não sofreu influência da proximidade partidária do prefeito com o governador. Por outro lado, a fragmentação da Câmara dos Vereadores apresentou significância somente no primeiro modelo; no entanto, verifica-se uma relação controversa na medida em que os resultados mostram que a fragmentação do Legislativo é um fator que impacta positivamente o incremento da capacidade administrativa, contrariando a premissa teórica. Do mesmo modo, a variável competição eleitoral diverge do esperado, pois possui uma relação inversa ao aumento da provisão municipal de serviços, ou seja, quanto mais acirradas são as 
eleições, piores os desempenhos. Nesse caso, o resultado se aproxima mais do argumento de Mueller e colaboradores (2009), isto é, quanto maior a competição partidária, maior o ganho pessoal e menores os benefícios públicos (menor desempenho da política pública), devido à imprevisibilidade de reeleição.

O fato de a prefeitura ser governada pelo PT apresenta uma relação positiva, indicando que nesses municípios o indicador de provisão de serviços tende a aumentar cerca de 0,03 em relação às demais municipalidades. Podemos supor dois motivos para essa performance diferenciada: o alinhamento partidário com o governo federal foi um determinante e/ou o partido dos trabalhadores possui um comprometimento maior com esta política social.

Observam-se ainda que as variáveis municípios pertencentes às regiões Norte e Nordeste, quadro funcional da administração pública e situação econômica do município não apresentaram significância estatística nenhuma. A última talvez não seja o melhor indicador de renda dos municípios, pois em muitos deles os recursos podem ser concentrados. Entretanto, o porte populacional obteve efeitos nos dois modelos, o que não é uma surpresa haja vista que, quanto maior a população, maiores são as demandas por políticas públicas e também as condições das prefeituras em prover serviços públicos.

Por fim, anos de estudo é o indicador entre as variáveis independentes da pesquisa que mais reflete as condições sociais da população, porém os resultados dos modelos também são ambíguos. A expectativa era que houvesse uma relação negativa, o que indicaria maior evolução em áreas mais carentes da atenção governamental; contudo, embora os parâmetros de estimação tenham apresentado os valores próximos, no modelo de provisão de serviços a relação foi negativa enquanto que em capacidade administrativa foi positiva.

\section{Considerações finais}

A abordagem dos resultados de um processo de transformação na política de assistência social é oportuna não apenas em função da crescente relevância que esse objeto de estudo possui dentro do sistema de proteção social brasileiro, mas também devido ao estágio inicial da prática avaliativa das políticas públicas no país.

A pesquisa se preocupou em analisar três aspectos centrais acerca das consequências da criação do Suas. Para tanto, foram adotadas estratégias de avaliação inter-relacionadas fundamentadas numa abrangente base de dados empíricos. É importante ressaltar a existência de ameaças à validade interna da pesquisa, em função da ausência de medidas regulares de AS e de informações anteriores ao ano de 2005. Não obstante, o artigo procurou contornar esses obstáculos elaborando indicadores que, mesmo não sendo perfeitos, possibilitam mensurar as características da gestão municipal dessa política pública com os dados disponíveis.

Os resultados sugerem que o processo de implantação de um novo modelo de gestão descentralizada após 2005 foi, apesar de discreto, bem-sucedido tanto na expansão das condições operacionais das prefeituras quanto na provisão de serviços assistenciais. Além disso, 
nesse segundo aspecto, foi possível identificar que houve redução da disparidade entre os municípios. Todavia, o fator mais importante foi justamente o fato de que a evolução da política nos quatro anos analisados foi mais concentrada em cidades que apresentavam piores desempenhos na gestão da assistência social.

Tais resultados sugerem que a estratégia de municipalização da política de assistência social foi bem-sucedida nos primeiros anos da implementação do Suas. O novo modelo procurou incorporar o aprendizado da descentralização das políticas sociais mais estruturadas do país, educação e saúde. Em outras palavras, a indução à cooperação federativa também se fundamentou em uma estrutura de incentivos e constrangimentos que fomenta a participação dos governos subnacionais dentro de um processo de negociação e adesão voluntária.

Os modelos de regressão múltipla trouxeram algumas constatações importantes acerca dos determinantes desse processo. Se, por um lado, o fator político apresentou alguns resultados contraditórios no tocante à fragmentação do Legislativo e competição política, por outro, indicou que prefeituras do PT demonstraram desempenhos diferenciados dos demais partidos. Esse fato, entretanto, para ser precisamente explicado merece pesquisa futura que aborde de forma mais detalhada o relacionamento entre os governos (federal e municipal) na implementação da AS. Por fim, cabe reiterar que fatores que notoriamente poderiam influenciar no desenvolvimento de uma importante política social, tais como o quadro funcional da prefeitura, condições socioeconômicas e o fato de os municípios pertencerem a regiões historicamente menos desenvolvidas, não demonstraram serem variáveis determinantes desse processo.

\section{Referências}

ARRETCHE, Marta; RODDEN, Jonathan. Política distributiva na Federação: estratégias eleitorais, barganhas legislativas e coalizões de governo. Dados: Revista de Ciências Sociais, v. 47, n. 3, p. 549-576, 2004.

CAPORASO, James A.; ROOS, Leslie L. Quasi-experimental approaches: testing theory and evaluating policy. Evanston: Northwestern University Press, 1973.

CAVALCANTE, Pedro; NOGUEIRA, Ronaldo. Avaliação e monitoramento: institucionalização na gestão das políticas públicas do governo federal. Revista de Políticas Públicas e Gestão Governamental, v. 9, n. 1, p 25-41, 2010.

COOK, Thomas; CAMPBELL, Donald. Quasi-Experimentation: design and analysis issues for field settings. Boston: Houghton Mifflin, 1979.

COSTA, Frederico; CASTANHAR, José. Avaliação de programas públicos: desafios conceituais e metodológicos. Revista da Administração Pública, Rio de Janeiro, v. 37, n. 5, p. 969-992, set./out. 2003.

COX, Gary; MCCUBBINS, Mathew. Electoral politics as a redistributive game. Journal of Politics, v. 48, p. 370-389, 1986. 
GOLOSOV, Grigorii. The effective number of parties: a new approach. Party Politics, v. 16. n. 2, p. 171-192, 2010.

HOFFERBERT, Richard. The reach and grasp of policy analysis: comparative views of the craft. Tuscaloosa: University Alabama Press, 1990.

IMBEAU, Louis; PÉTRY, François; LAMARI, Moktar. Left-right parties ideology and government policies: a meta-analysis. European Journal of Political Research, v. 40, p. 1-29, 2001.

JACCOUD, Luciana; HADJAB, Patrícia; CHAIBUB, Juliana. Assistência social e segurança alimentar: entre novas trajetórias, velhas agendas e recentes desafios (1988-2008). In: IPEA. Políticas sociais: acompanhamento e análise. Brasília: Ipea, 2008. MINISTÉRIO DO DESENVOLVIMENTO SOCIAL. MDS. Política Nacional de Assistência Social — PNAS e Norma Operacional Básica NOB/Suas. Brasília, 2005.

MINISTÉRIO DO DESENVOLVIMENTO SOCIAL. MDS. Financiamento da Assistência Social no Brasil. Caderno Suas, Brasília, n. 4, 2009.

MUELLER, Bernardo et al. The choices governors make: the roles of checks and balances and political competition. No prelo, 2009.

ROOS, Naralou. Evaluation, quasi-experimentation and public policy. In CAPORASO, James A.; ROOS, Leslie L. Quasi-experimental approaches: testing theory and evaluating policy. Evanston: Northwestern University Press, 1973. p. 281-304.

STEIN, Ernest et al. A política das políticas públicas. Rio de Janeiro: Elsevier, 2007. cap. 1, p. 11-22.

TREVISAN, Andrei; VAN BELLEN, Hans. Avaliação de políticas públicas: uma revisão teórica de um campo em construção. Revista de Administração Pública, Rio de Janeiro, v. 42, n. 3, p. 529-550, maio/jun. 2008.

TROCHIM, William; DONNELLY, James. The research methods knowledge base. $3^{\text {rd }}$ ed. Cincinnati: Atomic Dog Publishing, 2008.

WEISS, Carol. Have we learned anything new about the use of evaluation? American Journal of Evaluation, v. 19, n. 1, p. 21-34, 1998.

WORTHEN, Blaine; FITZPATRICK, Jody; SANDERS, James. Avaliação de programas: concepções e prática. São Paulo: Gente, 2004.

Pedro Cavalcante é doutor em ciência política pela Universidade de Brasília (UnB). E-mail: cavalcante. pedro@gmail.com.

Beatriz Bernardes Ribeiro é doutoranda em administração pela UnB. E-mail: beautebr@hotmail.com. 


\section{Apêndice}

Tabela 2

Capacidade administrativa

\begin{tabular}{|lcccc|}
\hline \multirow{2}{*}{ Região } & \multicolumn{2}{c}{ Média } & \multicolumn{2}{c|}{ Desvio padrão } \\
\cline { 2 - 5 } & 2005 & 2009 & 2005 & 2009 \\
\hline Norte & 0,48 & 0,54 & 0,11 & 0,12 \\
Nordeste & 0,49 & 0,57 & 0,10 & 0,10 \\
Sudeste & 0,50 & 0,58 & 0,11 & 0,11 \\
Sul & 0,51 & 0,56 & 0,11 & 0,11 \\
Centro-Oeste & 0,49 & 0,57 & 0,11 & 0,10 \\
Brasil & 0,50 & 0,56 & 0,11 & 0,11 \\
\hline
\end{tabular}

Fonte: Suplemento AS da Munic/IBGE de 2005 e 2009. Elaboração própria.

Tabela 3

Provisão de serviços

\begin{tabular}{|lcccc|}
\hline \multirow{2}{*}{ Região } & \multicolumn{2}{c}{ Média } & \multicolumn{2}{c|}{ Desvio padrão } \\
\cline { 2 - 5 } & $\mathbf{2 0 0 5}$ & $\mathbf{2 0 0 9}$ & $\mathbf{2 0 0 5}$ & $\mathbf{2 0 0 9}$ \\
\hline Norte & 0,48 & 0,54 & 0,25 & 0,25 \\
Nordeste & 0,53 & 0,64 & 0,24 & 0,21 \\
Sudeste & 0,57 & 0,59 & 0,26 & 0,22 \\
Sul & 0,62 & 0,59 & 0,26 & 0,20 \\
Centro-Oeste & 0,60 & 0,61 & 0,24 & 0,22 \\
Brasil & 0,56 & 0,59 & 0,25 & 0,22 \\
\hline
\end{tabular}

Fonte: Suplemento AS da Munic/IBGE de 2005 e 2009. Elaboração própria. 
